\title{
Gene editing CRISPR/Cas9 system for producing cows with hypoallergenic milk on the background of a beta-lactoglobulin gene knockout
}

\author{
Yulia Yu. Silaeva ${ }^{1 *}$,Marina $V$. Kubekina $^{1}$, and Alexandra $V$. Bruter ${ }^{1}$, Albina G. Isaeva ${ }^{2}$, \\ Andrey G.Koshchaev ${ }^{23}$ \\ ${ }^{1}$ Core Facility "Genome editing", Institute of Gene Biology of the Russian Academy of Sciences, \\ 34/5, 119334, Vavilova str., Moscow, Russia \\ ${ }^{2}$ Ural Federal Agricultural Scientific Research Center of Ural Department of Russian Academy of \\ Sciences,620142, Belinskogo,112 A, Ekaterinburg, Russia \\ ${ }^{3}$ Kuban State Agrarian University, 350044, KalininaSt., 13, Krasnodar, Russia
}

\begin{abstract}
Beta-lactoglobulin is the main allergen of cow's milk. Modern approaches to reducing the allergenicity of milk require significant costs for its fermentation. An alternative approach could be the creation of productive breeds with a knockout for the gene of this protein. This will allow, at no additional cost, to increase its safety for children who are breast-fed. In this article, we report on the development of a system for gene editing to create cows with a knockout of the beta-lactoglobulin gene.
\end{abstract}

\section{Introduction}

BLG is the main allergen in cow's milk, and about $3 \%$ of infants and young children suffer from allergies to cow's milk [1], while complementary foods using whole milk can provoke severe diseases [2]. Removing BLG from cow's milk reduces its allergenic potential and increases its potential as a food product for young children. To date, the main way to reduce the allegricity of milk mixtures is deep denaturation of proteins. In fact, we are talking about a mixture of peptides, but this can lead to the formation of new allergenic epitopes. A modern alternative is approaches for creating animals with a knockout of the BLG gene[3,4]. It is especially important to carry out such work on industrial breeds of cows, because it allows you to make a specific feature, allows you not to affect other economically significant features and productivity. Previously, work was carried out combining transgenesis, gene knockout and SCNT, as well as TALEN and microinjection into the pronucleus. All of them showed sufficient effectiveness. The rapid development of crispr/Cas9 gene editing technology $[5,6]$ allows us to count on the effective introduction of mutations in the BLG gene in cattle breeds used in production. In this paper, we present the results of the development and creation of a system for introducing a double-stranded

${ }^{*}$ Correspondingauthor: $\underline{\text { silaeva@genebiology.ru }}$ 
gap in the BLG gene, which, as a result of repair, is highly likely to lead to a knockout for this gene.

\section{Materials and methods}

Guide RNA cloning was performed in the px330 vector (Addgene, https://www.addgene.org/crispr/zhang/) in accordance with the manufacturer's instructions. The vector was cut using BbsI-HF restrictase (New England Biolabs), dephosphorylated using FastAP enzyme (Thermofisher Scientific), then purified in agarose gel and then isolated using the Monarch DNA Gel Extraction Kit. Oligonucleotides containing a sequence of guide RNAS were synthesized by Eurogen.

\section{5' - CACCGNNNNNNNNNNNNNNNNNNN - 3'}

3' - CNNNNNNNNNNNNNNNNNNNCAAA - 5',

Scheme of oligonucleotide synthesis for cloning guide RNA. Added nucleotides to complement the sticky ends formed when cutting the px330 vector with BbsI-HF restrictase $[7,8]$.

The oligonucleotides were phosphorylated using the PNK kinase enzyme (Thermofisher Scientific), annealed with each other, and ligated with the previously prepared vector and using the T4 DNA ligase enzyme (Thermofisher Scientific). The ligase mixture was transformed into competent cells of the XL1blue strain (Eurogene). The colonies were screened using Isogen PCR kits. Two colonies each containing sgrna were grown in the night culture and isolated using the Monarch Plasmid Miniprep Kit. Sequencing of the obtained plasmids was performed using the U6-forv primer by Eurogen. The sequencing analysis was performed using SnapGene software.

The research is executed at the expense of a grant of the Russian scientific fund (project No. 19-76-10022).

\section{Results}

Agilis gene - gene structure, introns exons, the knockout, $5 \mathrm{SG}$ on the list, discussing each position, off targets, the rationale for the selection of some kind (pic 1 - gen and the point of cutting the +1 tab - SG with the quality settings)

To generate a knockout of the gene bLG, it was decided to make a mutation in the promoter of the gene, since the gene itself was not quality RNA.

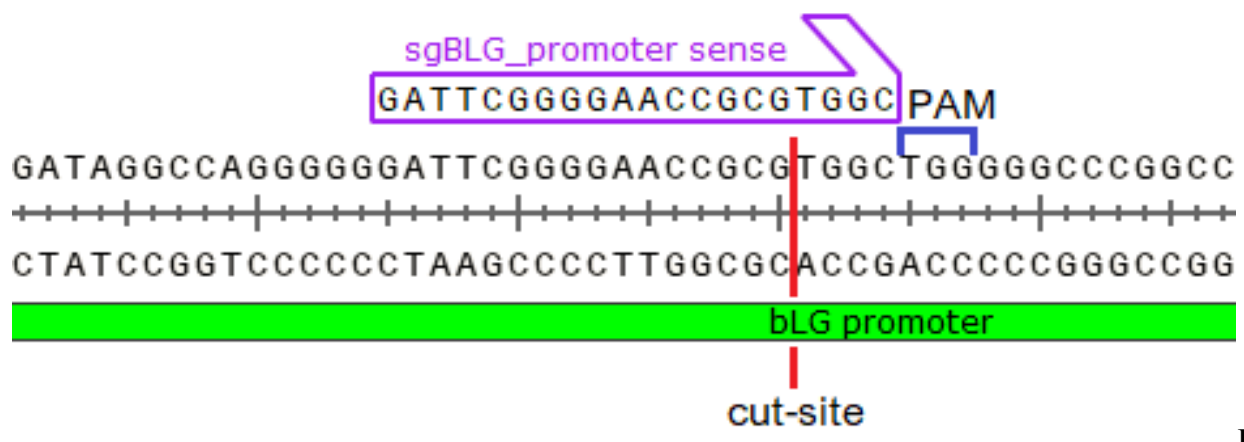

Fig.

1.Scheme for making a cut in the BLG gene promoter to create a knockout.

Table 1. sgRNAs for introducing a mutation in the BLG gene promoter.

\begin{tabular}{|l|l|l|l|l|}
\hline Position/ & Guide Sequence + PAM & MIT Specificity & CFD Spec. & Off-targets for
\end{tabular}




\begin{tabular}{|c|c|c|c|c|}
\hline Strand & & Score & score & $\begin{array}{l}0-1-2-3-4 \\
\text { mismatches }\end{array}$ \\
\hline 47 / fw & $\begin{array}{c}\text { GCCTCCTATTGTCCTCGTAG } \\
\text { AGG }\end{array}$ & 97 & 97 & $\begin{array}{l}0-0-0-2-32 \\
34 \text { off-targets }\end{array}$ \\
\hline $140 / \mathrm{rev}$ & $\begin{array}{c}\text { GTGGGCTCGGGGCCTTATAC } \\
\text { AGG }\end{array}$ & 95 & 97 & $\begin{array}{l}0-0-0-3-48 \\
51 \text { off-targets }\end{array}$ \\
\hline $104 / f w$ & $\begin{array}{c}\text { GATTCGGGGAACCGCGTGGC } \\
\text { TGG }\end{array}$ & 94 & 97 & $\begin{array}{l}0-0-1-1-31 \\
33 \text { off-targets }\end{array}$ \\
\hline $28 / \mathrm{rev}$ & $\begin{array}{c}\text { TCCTCTACGAGGACAATAGG } \\
\text { AGG }\end{array}$ & 92 & 96 & $\begin{array}{c}0-0-0-3-43 \\
46 \text { off-targets }\end{array}$ \\
\hline $105 / \mathrm{fw}$ & $\begin{array}{c}\text { ATTCGGGGAACCGCGTGGCT } \\
\text { GGG }\end{array}$ & 91 & 96 & $\begin{array}{l}0-0-1-5-28 \\
34 \text { off-targets }\end{array}$ \\
\hline
\end{tabular}

5 annual RNAS for introducing a mutation in the BLG gene promotershows in table 1 . The first one was selected $(104 / \mathrm{fw})$ as containing the smallest number of offtargets based on the results of the CRISPOR - Tefor program analysis. The scheme for making a cut in the BLG gene promoter is shown in figure 1.

A

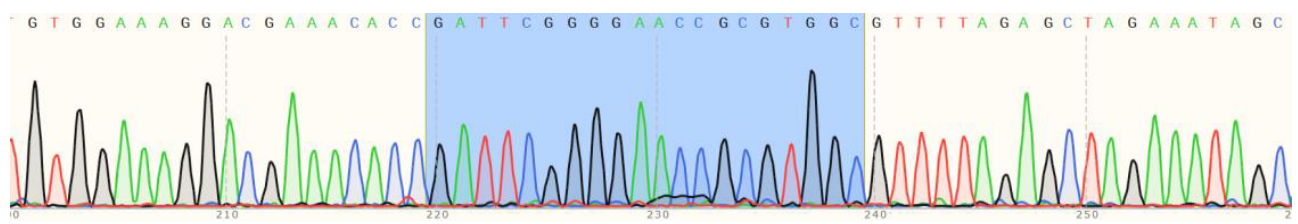

B

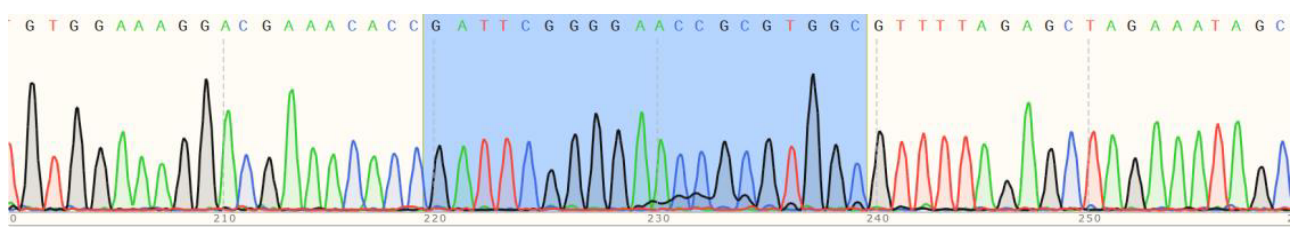

Fig.2.Sequence analysis of two (A and B) clones of plasmids pX330-bLG.

\section{Conclusion}

We performed bioinformatic analysis of the cattle genome in the area of bLG gene localization, analysed the sequences of potential target RNAS for the gene editing system, selected the most specific ones, performed molecular cloning and Sanger sequencing analysis of the quality of the obtained structures. Thus, a system for editing the cattle genome using CRISPR/Cas9 was developed to create animals that are knockout by the bLG gene. We assume that the resulting animals will not contain the beta-lactoglobulin protein in milk. 


\section{References}

1. A. Ann Høst, AllergyAsthmaImmunol, 89 (6 Suppl 1), 33-7 (2002)

2. R.A. Wood, S.H. Sicherer, B.P. Vickery, S.M. Jones, A.H. Liu, D.M. Fleischer, A.K. Henning, L. Mayer, A.W. Burks, A. Grishin, D. Stablein, H.A. Sampson, J Allergy Clin Immunol, 131 (3), 805-12, (2013)

3. A.V. Deykin, RussianScientist, 1 (2),16-17 (2017)

4. O.G. Maksimenko, A.V. Deykin, P.G. Georgiev, Acta Naturae, 1(16) (2013)

5. T.V. Dimitrieva, et al., Bulletin of Russian State MedicalUniversity, 3, 16-22 (2016)

6. T.V. Egorova, et. al., Diseasemodels \& mechanisms, 12 (4) (2019)

7. V.A. Kalmykov, et al., ResearchResults in Pharmacology, 4 (4) (2018)

8. Y.Y. Silaeva, V.A. Kalmykov, E.A. Varlamova et al., DoklBiochemBiophys, 490, 43$46(2020)$ 